\title{
Ecological sensitivity within human realities concept for improved functional biodiversity outcomes in agricultural systems and landscapes
}

\author{
Melissa Anne Beryl Vogt (iD ${ }^{1 凶}$
}

Sustainable agricultural landscapes seek to improve environmental, societal and economic outcomes locally and internationally. They depend on functionally biodiverse agricultural systems, i.e., systems that include diversity in plants and/or crops and maintain productive function. These systems are variably defined and are not adequately or consistently represented or ensured across agricultural landscapes. The variability results in inconsistent productive function, and minimally biodiverse agricultural systems and landscapes that degrade the environment, preventing consistent increases in functional biodiverse systems across farming landscapes and impeding long-term societal and economic benefit. The article answers the question: how can the Ecological Sensitivity within Human Realities (ESHR) concept improve consistent and more thorough increases in functional biodiversity outcomes from human natural environment interactions as a conceptual explanation. The ESHR concept for functional biodiversity is introduced and explained using an integrated narrative literature review. Motivation to develop and present the ESHR is an observed and identified need to emphasize the human influence on functional biodiversity outcomes and encourage sensitivity of human interactions with the natural environment through more detailed considerations that might better ensure consistent outcomes. Existing and commonly used concepts that seek to improve biodiversity in agricultural systems are compared to the ESHR to demonstrate novelty. New understandings of ecological and human conditions in coffee farming landscapes are not introduced, instead, the concept substantiates (1) functionally biodiverse agricultural systems rely on consistently functional ecological interactions and processes for all system and landscape complexities by structure, heterogeneity, and interactions, between and across systems; (2) human interactions are influenced by variability in the human condition across individuals and societal groups, referred to as human realities. When compared to the selection of existing concepts of similar intentions it demonstrates to combine strengths of different concepts with improved opportunity for contextual adaptations. Comparatively consistent, comprehensive considerations and functional biodiversity outcomes are encouraged and expected with the use of the ESHR. Recommendations for future use and research are provided.

${ }^{1}$ UNSW, Kensington, Australia. ${ }^{凶}$ email: Melissaanneberylvogt@gmail.com 


\section{Introduction}

uman natural environment interactions often adjust the environment in a way simplest for human management (Western, 2001). In areas where humans dominate, interactions can shape and overwhelmingly influence biodiversity outcomes through dramatic alterations (Ehrlich, 2009). Modification may be influenced by preferred crops, the health of farmers and families, aesthetic preferences, facilitated harvest, secured markets, or political or legal parameters and allowances (Vogt, 2019a). Within agricultural landscapes, agricultural expansion by subsistence, commercial or shifting agricultural practice (Geist and Lambin, 2002; Brawn, 2017; Lanz et al., 2018) are most influential to simplifying natural resource systems, causing deforestation and land degradation (Vogt, 2019a, c). Landscape context can change this outcome slightly (Sonter et al., 2017; Imai et al., 2009). While the rationale for variable landscape modification exists, a constant is a significant control humans have over environmental outcomes through such interactions. An improved understanding of functional biodiversity as a positive outcome more easily shapes human interactions with the natural environment

Functional biodiversity complements productive intentions and ensures robust agri-biodiverse systems ${ }^{1}$ that rely on ecological interactions and processes (Bullock et al., 2017), dependent in part on genes and species present, their diversity and abundance, and then spatial distributions. Ecological interactions and processes are considered a 'foundation' or 'fusion point' (Leopold, 1939) across agricultural landscapes (Forman, 1995) for biodiversity outcomes. The varying definitions of biodiversity used across and within disciplines, and locations (Wilson, 1988; Delong, 1996; Holt, 2006; Cerda and Bidgeain, 2018) variably consider ecological conditions as an explicit or necessary associated factor. They are however considered essential for positive environmental outcomes. Agricultural systems that include biodiversity can be minimally biodiverse, and the biodiversity included can variably ensure maintained productive or biodiversity function of an agricultural system or landscape (Vogt, 2017, 2019a). Biodiverse systems can then remain productive without ecological functional traits instead of relying on external inputs. Natural stability and long-term function are not therefore guaranteed.

Consistent ecological considerations for functional biodiversity are therefore required, not only within specific projects or studies but in a more consistent and wide-reaching way for system and landscape conservation and productive function (Letourneau and Bothwell, 2008; Bullock et al., 2017). While ecological aspects of a human-modified productive landscape are relevant, the human aspects are also essential considerations in terms of influence on landscape modification and for functional biodiversity.

A concept that brings attention to a positive outcome with adequate detail is considered useful and can provide front of mind guidance for assessing, understanding, and planning future human-natural environment interactions. The attention to a concept can be compared to a paradigm setting, which is often considered a key influencer for shaping human interactions with other people and with the natural environment (Cohen, 2015). The simplicity of a concept can facilitate accessibility for different stakeholders improving reach and relevance across various 'locations' of stakeholder interest, and understanding as a preliminary yet significant advance toward implementation and desired outcome. Balancing between generalisability and specificity for intended outcomes is however necessary, particularly for concepts that include principles and details of ecological science (Johnson and Lidstrom, 2018). A frame for implementation is distinct to a concept through the provision of a methodology for implementation and understanding alignment of particular situations or practices (Jabareen, 2009). A more specific concept, before a complementary framework or frame for implementation to guide human interactions is suggested as valuable. There is therefore no inclusion of a framework in this article, with attention going to explaining the new concept only.

Shaping human-natural environment interactions to more consistently consider these two aspects, ecological conditions and human realities, for functional biodiversity is essential and provides motivation for the ESHR as a concept and for the article.

The article introduces the ecological sensitivity within human realities (ESHR) concept to assess and shape humannatural environment interactions in agricultural landscapes and improve functional biodiversity outcomes and explains the basis for development. In doing so it satisfies a research aim: to introduce a new concept that can encourage more consistent and thorough increases in functional biodiverse systems and landscapes resulting from human natural environment interactions using coffee farming as the example; by answering the question: how can a more specific concept improve consistency in functional biodiversity outcomes in agricultural systems and landscapes? The concept facilitates consistent guidance to manage a paradox of interest. Productivity for trade purposes can maintain without natural system function, and with significant negative environmental influence (Vogt, 2019b). It is general enough to allow for the contextual differences resulting from agricultural landscapes but specific enough to ensure adequate attention and detail is given to required areas.

The methods and methodology used to develop the concept, grounded ethnography, and the approach to article write-up, integrated narrative review, are explained. The results provide a conceptual explanation of the ESHR including the definition of sensitivity used and of functional biodiversity, then of the two aspects of the ESHR, (I) Ecological interactions and process, and (II) Human realities as relevant to any agricultural landscapes. The concept is then explained specifically to coffee farming landscapes Coffee farming landscapes explain a landscape that includes a significant proportion of hectares dedicated to coffee farming.

The results do not apply the concept, as publications already do conceptually, see Vogt (2019a, 2020, 2021) and sections "Examples of combined considerations as relevant to the ESHR"; "Farm design and human realities of the ESHR"; and "ESHR and conceptual understandings of coffee quality and market value" and "Farm design, and ESHR considerations for coffee farming landscapes". Existing explanations of the ESHR already published with reference to the work of foundational ecological science scholars work including Holling (1973); Ostrom (1990) and Gunderson (2000), can be found in Vogt and Englund (2019) and is not repeated.

The discussion summarises results and situates and compares the ESHR to concepts of similar specificity and intention, demonstrating relevance, contribution and novelty of the ESHR for research and practice. Four existing, specific and relevant concepts for the agricultural context, socio-ecological niches, sustainable intensification, ecological intensification and ecosystem services were selected according to similar specific intention to the ESHR. Three other concepts, biodiversity, societal considerations and landscape ecology are defined and basic explanations of comparison with the concept are also provided. Recommendations for future research and practice are provided in the conclusion. 


\section{Methods}

To conceptually explain and introduce the ESHR concept, the integrated narrative review is used. The approach combines information from the grounded ethnographic process used to develop the concept with additional literature review, cogitation and presentation. The approach is conducive for presenting the combination of methodology and methods used to develop and then describe the concept, compared to a systematic literature review and cogitation, or only presenting fieldwork findings. Comparisons to specific and more general commonly used and relevant concepts are provided in the discussion based on a simple literature review and cogitation. These comparisons provide an explanation of novelty and contribution amongst existing concepts of similar use. The following subsections explain the sources of information used to present the integrated narrative review.

Grounded ethnography for concept development. Grounded ethnography requires an ongoing process of information collected through fieldwork and literature, and ongoing comprehensive reflection and triangulation of all types of information collected through the fieldwork and reflection process. Methods and methodology used through fieldwork in Cuba and Costa Rica in 2014 informed a grounded ethnography. S1, Supplementary information, provides more information about fieldwork and the grounded ethnography process. To summarize the methodological process resulting from methods used in the field and after fieldwork, fieldwork reflections and six foundational observations from fieldwork reflections provide a simple overview of the thought process that provided initial grounding for concept development. The six observations from fieldwork were noted before and during the development of the ESHR concept. They formed a more specific basis for understanding biodiversity in coffee systems and landscapes, guided literature review strategy and developed the ESHR concept as part of the methodological process.

Fieldwork reflections. Coffee does not contribute to food supply, and inconsistently to farmers' economic benefit (ICO, 2018). At the time of fieldwork, in 2014, the importance given to coffee, particularly through conventional monoculture farming was a curiosity. The curiosity increased where diverse crop systems in coffee farming landscapes of Cuba and Costa Rica were able to reliably produce with limited external synthetic inputs. These diverse systems were not always intended for commercial production, and yields and crop density were not excessively high. Many of these more diverse, by crop, plant and tree diversity, systems had however easily survived through difficulties that frequently resulted in abandoned conventional coffee farms, such as the special period in Cuba, resulting in mass internal migration and wide-ranging famine (PAHO, 2002; Rosset and Benjamin, 1994); the coffee crisis in Costa Rica in 2001 and previous green revolution approaches that resulted in food shortages (Vogt, 2019b; Babin, 2015), while producing subsistence food for the farmer and perhaps for some of the community. The benefit of more crop diverse systems is clear from these examples but ensured commercial productivity and income is an identified barrier to increasing the presence of such systems across a landscape. Where seeking to improve positive biodiversity outcomes in these landscapes, the continuing need to produce coffee by yield quantity as a cash crop is considered a significant common perspective or orientation, and potential constraint to improving biodiversity outcomes (Vogt, 2019c).
Six observations from fieldwork that formed a basis for concept development. Six observations made in-field peaked interest as important influences for positive environmental outcomes within a coffee farming context. These observations are not obviously or consistently implemented or considered across the coffee farming landscapes visited, nor amongst common understandings, concepts or literature. Where understanding was evident, a gap between understanding and confidence in viability for biodiverse coffee farms remained. They include (1) Ecological conditions for biodiversity outcomes; (2) Ecological conditions across spatial scales; (3) Shade and groundcover; (4) How biodiverse systems could attend to or resolve existing community and country-level societal issues; (5) How crop quality is defined and recognised as associated with market value and biodiversity; and (6) How biodiverse systems consider human capability. These observations are explained in detail (see s2, Supplementary information).

Literature for narrative review. Selected literature reviewed from 2013-2018 is integrated through results and discussion. Literature review specific to demonstrating how coffee shade and ground cover and biodiverse coffee farms are often represented in the scholarly literature by frequency and definition is based on specific search terms (see s3, Supplementary information), and was completed for the purpose of the article. The search term results demonstrate how biodiversity is understood and often represented in scholarly literature for the coffee farming landscape context and provides additional rationale for the ESHR concept, relevant to all six observations from fieldwork, specifically to observation 3, and to the functional biodiversity objective of the concept. Specifically, tier 2 of rationale provided. The findings from search term result further justify fieldwork informed studies, integrating findings from fieldwork into publication, and combining existing desk-based information, satellite imagery, academic and industry literature with fieldwork findings for more extensive and comprehensive research-informed practice and explanation of the state of the field.

To situate and compare the ESHR with the existing concepts, general and specific, targeted literature search and selection was conducted, with citation included. It is recognised that the use of each concept, general or specific can differ from what is in literature. Basic and more recent literature explanations were therefore considered acceptable. A summative explanation of social and ecological concepts is provided in s6, Supplementary information.

Figures, images and tables. Table 1 provides summative explanations of human realities considerations. Table 2 of specific explanations for each of the study countries. Complementing specific explanations for the coffee farming landscape context, Figs. 1 and 2 provide photos of two example farms from each study country. They have different types of functional complexity and are explained as aligned with the two aspects of the ESHR, Table 3 provides extended explanations of system output and human realities considerations for each image. Figure 3 situates and compares four specific and relevant concepts with the ESHR by the diagram. Tables 4 and 5 provide definition and basic comparisons of seven relevant concepts, the four specific concepts and three more general with the ESHR with a more detailed explanation of the comparisons provided in the following paragraphs.

Table s3.1 and s3.2, Supplementary information, provide search terms, the rationale for inclusion, advance search criteria and quantified search term results. Figure s4.1, Supplementary information, visually explains the new use of ecological sensitivity compared to other existing uses of the term. Figure s5.1, 


\section{Table 1 Explanation of human realities for coffee farming landscape.}

\section{Common human realities across coffee farming landscapes: within farmer control}

The shared experience of farming coffee over centuries and generations provisions a similar culture across coffee farming landscapes, often increasing interest in maintained coffee farming (Vogt, 2019b). As farmers are often most directly interacting with the natural environment, commonalities between coffee farming landscapes are presented as within the control of the farmer, determined by preferences indirectly influenced by various factors.

\section{Interest: an intangible human reality influential to and influenced by tangible human realities}

The value of nature for humans (Pascual et al., 2017) does not always positively associate with agricultural production. Subsequently, conventional intensive agricultural practices and associated yield homogeneity can remain dominant, and biodiverse agricultural systems limited. Land degradation within intensive agricultural patches and for neighbouring patches are not often considered but can be significant in terms of environmental damage (Vogt, 2021). The benefit and implication of increasing functional biodiversity within coffee systems and landscapes is therefore an important human reality to address. An improved understanding of how (1) yield is influenced by biodiverse coffee farms, and (2) the required adjustments in maintenance, harvest and aesthetics of a system can ultimately influence interest, and improve uptake of interactions guided by the ESHR, subsequently, functional biodiversity outcomes. Interest can ensure adequate attention to tangible human realties ${ }^{\mathrm{a}}$ (3) access to resources and (4) capability, these realities are understood as variably within farmer control.

\section{Intangible human realities}

\section{Productivity: yield and biodiversity}

Yield quantity decreases are often associated with reduced economic benefit, a deterrent for farmers and other stakeholders.

External inputs can ensure artificial system stability and maintained yield for agricultural production. Artificial system support is more likely relied on when biodiversity is understood to compromise yield quantity (Bommarco et al., 2012; Shennan et al., 2017; Fischer et al., 2017). The combination of factors means that biodiverse systems are often considered unnecessary within productivity terms. (i) Increases in a systems' functional biodiversity will not necessarily result in decreased yield quantity or quality (Vogt, 2019c); (ii) System and landscape functional ecological conditions for productive intentions clarify inconsistent not consistently negative influences of biodiversity on yield (Innes et al., 2013); (iii) Biodiversity, productive intention dichotomy is capable of compromise. Particularly so where the yield can be re-considered within commercial terms (Vogt, 2020); (iv) Improved understanding of how functional biodiversity is conducive to productive intentions (Weiner, 2017) can significantly influence intangible realities; ( $v$ ) Where complementarity between biodiversity and productive intentions is understood, ideas of trade-offs between agricultural land use and the natural environment can reduce ( $V$ ogt,

2021, p. 2)
Tangible human realities

In-between

\section{Access to resources}

Access to necessary resources is relevant for all The range of stakeholders involved in the coffee contexts and situations at system and landscape levels.

(i) Resources can be seeds, plants and crop varieties, biological control agents, natural or synthetic inputs to maintain agricultural system function, labour, learning material or other technologies. (ii) Access is different not only by country and landscape or region but also by the farm and farmer, and their relationship with particular stakeholders or their personal financial, education or societal situation. See 'beyond farmer control'.

\section{industry, and myriad interests represented} provides a group of stakeholders that are externally influential to farmer preferences and practices.

The stakeholder realities of commercial need, production priority.

\section{Aesthetics, maintenance and harvest preferences}

In a situation where 'external' stakeholder influence is equal, and understanding of biodiversity's contribution to productivity is clear, resistance to increasing biodiversity within agricultural systems and landscapes can be further influenced by aesthetic, management and harvest preferences as intangible realities.

- Harvest implication and maintenance requirements and aesthetic preferences contrary to more biodiverse systems can influence interest. For example, traditional science and conventional agriculture critique of biodiverse systems as 'messy' and more difficult to manage and harvest from can significantly influence resistance to diversified farm and landscape systems.

- Less advanced examples of biodiverse coffee systems can negatively influence the understanding of the benefit of biodiversity and subsequently intangible realities.

\section{Capability}

Capability ensures any change in system or landscape configuration is successful, and long-term functions more likely. It ensures understanding of different management, visitation and harvest approach required (Vogt, 2019a). The importance of farmer capability indirectly draws attention to generational techniques that maintain and harvest biodiverse coffee systems. Generational techniques are distinct to indigenous farming (Vogt, 2019a, pp. 7-9; p. 13). The benefits of agricultural systems that respect and make the most of generational techniques can further contribute to capabilities (Vogt, 2019a) that sustain functional biodiversity outcomes (Lichtenberg et al., 2017; Vogt, 2019a) at the system and landscape level. (I) Groundcover has implications for maintenance techniques and preferences, such as harvest. Shade cover also. (II) Hand versus machine harvest adds to these considerations. 


\section{Table 1 (continued)}

\section{Aesthetics, maintenance and harvest preferences}

\section{Capability}

- A dysfunctional system reduces beneficial contributions to the system and surrounding environment within the two aspects of the ESHR. For example, pine trees within coffee farms while appearing positive as a biodiversity outcome compared to a monoculture system can drop excessive pine needles and cover crop bases, limiting root access to water and other ground-based nutrients, with subsequent human maintenance requirements (Vogt, personal observation, 2014).

- Addressing how more biodiverse systems can be designed to accommodate aesthetic preference, and facilitate harvest and maintenance can assist (Vogt, 2019a; Fig. s5.2, Supplementary information). Preferences are expected to differ according to the system and landscape context.

\section{Varying human realities across coffee farming landscapes: beyond farmer control}

Varying interactions with and differences between landscapes according to subtler details of history, politics, policy, economic, culture, and landscape specific experiences, including responses to common and different challenges experienced, are human realities that vary between the two countries and in each coffee farming landscape. Differences often result from human realities that are within farmer control. For example, the needs and opinions of farmers have been studied to determine how to best bring about change in opinion and practice. While similarities between farmers' needs and preferences exist, they are contextual, and the context is based on prominent crop, landscape or country, and then circumstance. In some cases, slow change is necessary or preferred. In other situations, rapid change is preferred and in extreme circumstances necessary, if they want to continue farming. These external factors are beyond the control of a farmer but their response to these situations is at some level within their control. There are then other external factors that are beyond farmer control and not as circumstantial.

\section{Tangible human realities influential to and influenced by intangible human realities}

\section{Interaction with the international market}

A cooperative will often interact directly with international markets, independent farmers might also, or through a middleman. Each situation represents varying levels of control a farmer has over sales and farming practices.

Direct involvement with international or local markets may provide exposure to new ideas and opportunities, influenced by the stakeholder they interact with. Where buyers seek 'sustainably' grown coffee, improved environmental outcomes are expected. Influenced by the definition of sustainability understood and the trade approach used (Vogt, 2019b, 172). In other cases, the buyer might be concerned with the quantity and quality of the harvest remaining the main selection criteria (Vogt, 2019c). In the two study countries, international trade is regulated differently. See Table 2 for an example of the difference between countries.

\section{Access to plant and crop varieties}

A more centralized governance structure can significantly restrict and influence accessibility to plant and crop varieties within particular regions according to agricultural planning and policy. Decentralised governance structures might restrict agricultural planning and policy in a less organised way. For both types of governance systems, restrictions in access can emerge due to physical geography, or market demand and buyer trends. From fieldwork observations, market demand demonstrates as a common and significant influencing factor no matter the governance structure. The governance structure had a significant influence on permitted crops and plants within particular regions. See examples in Table 2.

aAttention for this article stays with existing agricultural systems or degraded agricultural systems and landscapes that might be converted to a coffee system. It is however recognised that interest within intangible human realities may influence continued coffee farming compared to other activities. Relevance to the concept for this situation remains according to how generational knowledge of systems that might be converted for other land uses can be conserved and used for the benefit of increasing biodiversity in neighbouring coffee systems.

Supplementary information brings together findings from literature review and fieldwork as a generic reference for variations in coffee systems, providing additional detail to those previously provided in scholarly literature. Figure s5.2, Supplementary information, can easily be cross-referenced with farm images provided in Figs. 1 and 2.

\section{Results}

The results section explains the ESHR concept including explanations of functional biodiversity and sensitivity for the purpose of the concept. Then, as specific to coffee farming landscapes by combining fieldwork observations with literature. Two images of example farms are used to demonstrate different types of functional complexity. They are assessed and explained using the two aspects of the ESHR.

Ecological sensitivity within human realities (ESHR). Agricultural landscapes are ultimately a context of significant human interaction and presence, modifying the environment for productive intention. The Ecological Sensitivity within Human Realities (ESHR) concept guides assessment of and future human natural-environment interactions in agricultural landscapes to improve functional biodiversity outcomes. The idea of sensitivity to ecological considerations encourages an understanding of control humans have in agricultural systems and landscapes, different from existing definitions of ecological sensitivity, see s4 
Table 2 Examples of variable interaction with the international market, and access to plant and crop varieties from each study country.

\section{Cuba}

\section{Interaction with the international market}

\section{Costa Rica}

A farmer will not interact with an international buyer at all, their buyer is There is less such government regulation of international trade, plantation the government via a cooperative, officially. In some cases, and where farms located close to San Jose the capital are for example normally run as approved they may interact with a tourist as a buyer directly but varying a business trading directly with the international market, or selling to the degrees with the international market, and this relies substantially on the domestic market. Smaller farms particularly where the farmer and family size of the farm and the farmer network. lives on the farm will more likely trade with a cooperative who then sells to the international market directly. This may be through an above-tiered cooperative, an independent mill, or through a government broker. It is however open to farmer preference, and the varying examples of intangible and tangible realities provided above. There are examples of less preference for cooperative involvement and more involvement directly with domestic or international markets (Vogt, 2019d).

\section{Access to plant and crop varieties}

An example from Cuba, and available in the literature is the reliance on Legal restrictions and facilitated access to plants and crops are influential. It sugar production upon which Cuba survived up until the 1990s (Acosta, is not obligatory to participate in government agricultural programs, 1972; Diaz-Briquets and Perez-Lopez, 2000). A country can only survive however, the government does to complement agri-forestry intentions growing and exporting mainly one crop where trade arrangement ensures supply farmers with the tree, crop and plant start. At the time of fieldwork, sufficient income, and this was the case with the Soviet Union. In this situation, it was a combination of having to grow sugar to satisfy trade demand from the Soviet Union, the only trade option Cuba had after the revolution. The limited trade options and centralized governance approach con ensured an increase in agricultural land dedicated to sugar. In addition access to plant and crop varieties was limited to government supply and the black market. The fact that permission was required to grow other crops, means that even with access, growing any range of crops and plants could be illegal. While these restrictions have relaxed, laws and rules remain related to crop and plant varieties, and land use. The productive intention and requirement for economic gain also removed any environmental protection through farming and processing sugar. This has since reduced, particularly after the special period (Rosset and Benjamin, 1994).

\section{Summary}

- The examples indicate how a farmer may understand the value of their coffee and the subsequent influential sources that guide approaches to managing their farm. It is suggested that direct trade arrangements with farmers might improve interest and capability in 'sustainable' approaches (Vogt, 2019c, p. 172). Comprehensive sustainability programs run by national or international programs, as alternate influential stakeholder support for sustainability might also have a similar influence (Vogt, 2019c), another variable human reality for the coffee farming landscape.

- They are relevant for ecological considerations and functional agri-biodiverse systems and landscapes as influenced by productive intentions, and more specifically for shade and groundcover heterogeneity and system and landscape structure and function for coffee farming landscapes. Direct access to international markets and open access to plants and crops will not necessarily result in improved or reduced biodiversity outcomes, but they will condition these outcomes. The influence of market, economy and land use, and regulation of the two; and then farmer preference exists for the two considerations.

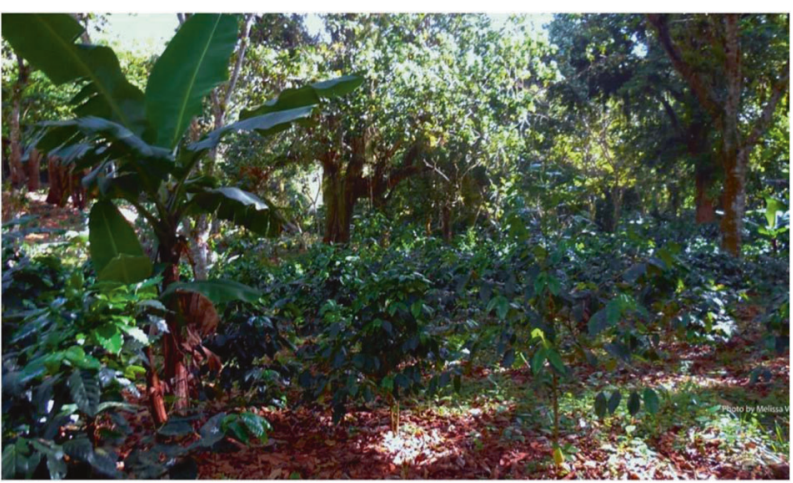

Fig. 1 Shaded monoculture with dead ground cover-leaf litter. Included in the system are banana, avocado, 2 varieties of shade trees and dead groundcover. Coffee farm in Cuba, 2014.

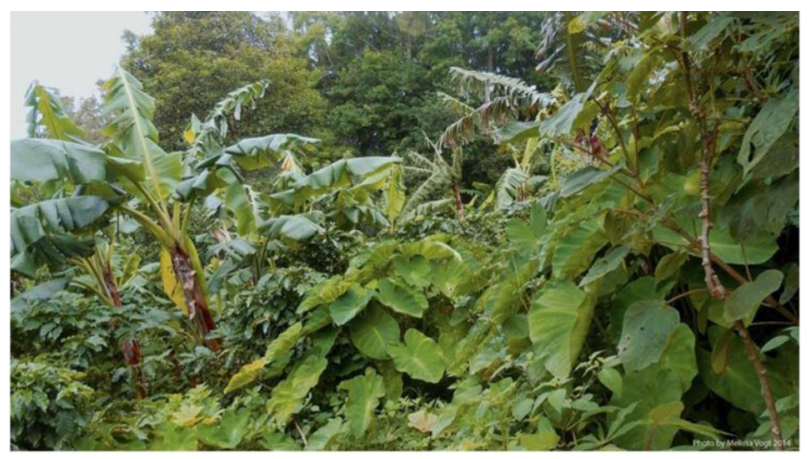

Fig. 2 Traditional polyculture 'Coffee Garden Forest' with living polyculture ground cover. Included in the system are 6 varieties of coffee; 15 different fruits, vegetables and medicinal plants. Vines and living ground cover. Coffee farm in Costa Rica, 2014. 
Table 3 Explanation of Figs. 1 and 2.

Figure 2 System output
Figure 1 System output

Function and ecological complexity Comparative human realities

The system in Fig. 1 is a simple shade The system in Fig. 2 includes up to 15 Both systems are functional in terms The difference in system structures and groundcover system intended to different foods, and medicinal plants of system stability, and coffee produce primarily if not only coffee. It integrated through both ground and production while maintaining may provide some bananas and shade cover, alongside the avocados as the few shade tree coffee yield. biodiversity, however, the structure and heterogeneity are different. evident by visual representation imply required management

varieties included in the system. It is The system is functional, stable and Referring to Fig. s5.1, Supplementary a restored coffee system, after significant abandonment and degradation from the 1990s.

The farmer has like many but not all

in the region, received technical support from the cooperative and

government. well managed, and the generational the owner of the farm. biodiverse agricultural systems, visits between different parts of the own maintenance and harvest information Fig. 1 is less complex supplemed kn 5.2

according to crop and plant diversity Figure 1 requires morning visits, and classified as a shaded monoculture. the farmer does not live on the farm, Figure 2 is of the most complex Fig. 2 by comparison requires routine classified as a traditional polyculture. farm, and different crops require their schedule. The farmer and family live on the farm, and the farm has been managed by the same family for two generations

An ability to create such a system, or conserve and expand similar existing biodiverse systems will be influenced and limited by layers of human realities in different ways.

The choice of creating and maintaining a more biodiverse agricultural system is significant and varies by country. It is of commercial or income orientated interest, as well as associated with the required personal investment, then by regulated practices.

International market demand and direct interaction might influence how interest in, and transfer of system capability progresses. Access to plant and crop varieties might also influence an ability to promote or replicate such a system or a more crop-diverse system.

Cuba has experienced food shortages, particularly related to nutritious foods. The system in Fig. 1 could therefore allow significant difference for local population food supply. Governed distribution of land use and farm production might also determine how farm produce is made available to the local community, how to crop diverse any agricultural system is, and how encouraged replicated Agri biodiverse systems and landscapes are. See Tables 1 and 2 for more explanations. and Fig. s4.1, Supplementary information. Sensitivity, therefore, encourages preventative and resolving interactions with the natural environment removing the assumption that existing difficulties created by human interactions are inevitable and not preventable. Human control determines sensitivity to ecological considerations, influenced by varying perspectives and situations.

There is not however one aspect of the human condition that can be shaped or adjusted, instead of different aspects that can be understood to address different contexts. To separate and better understand human realities as part of the concept, as aspects of the human condition, the intangible and tangible of human realities were introduced. The intangible human realities are less obvious or visible compared to the tangible, examples include interests compared to capability, and they are recognised as interrelated and mutually influential. Several human realities can be addressed through an effective understanding of functional biodiversity as reliant on ecological considerations.

The extent of sensitivity to ecological conditions for functional biodiversity in an agricultural system and landscape is determined by the contextual human realities of a country, landscape and/or farming community, or farm. How human realities change over time, how they form and specificity in understanding can ensure 


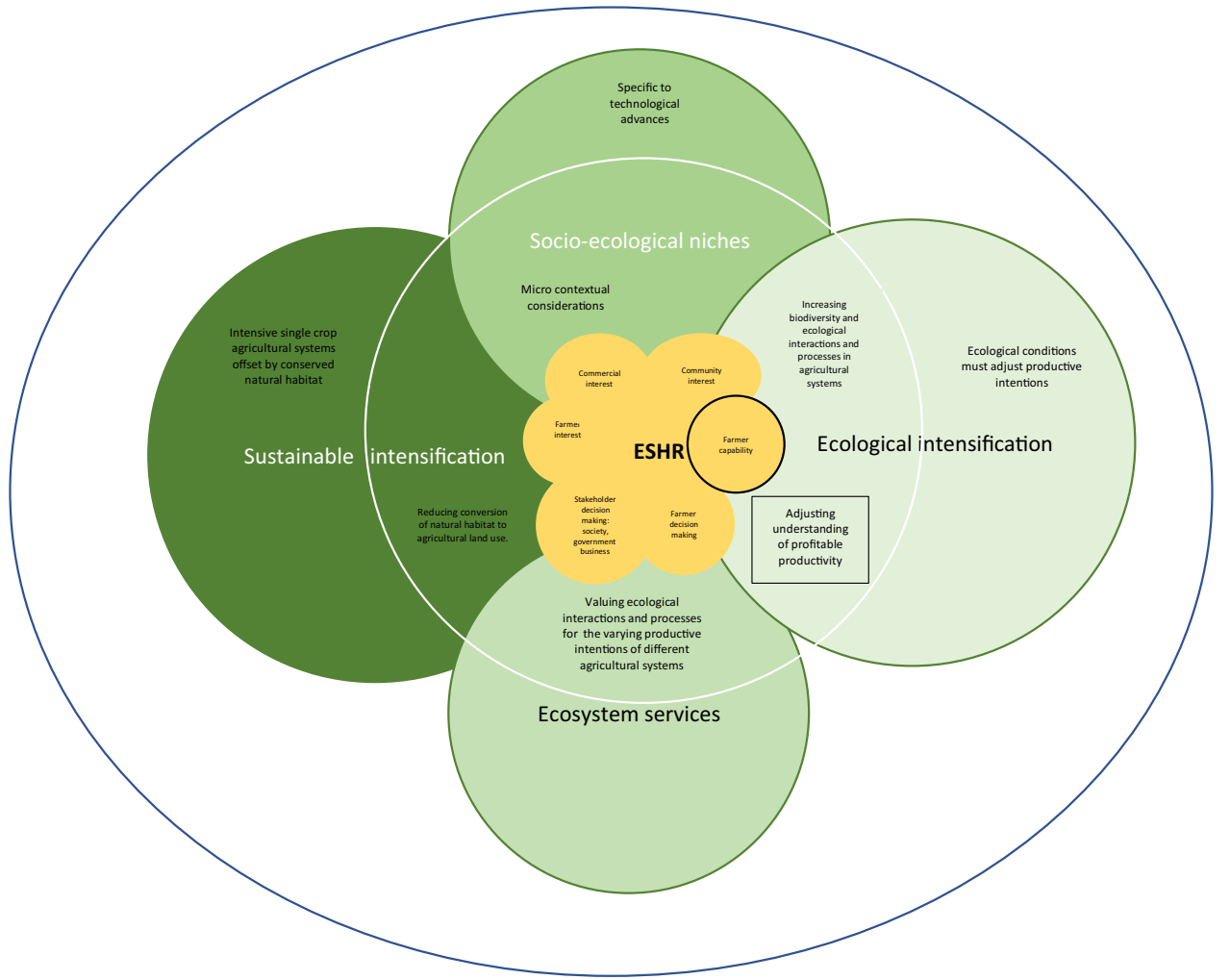

Fig. 3 ESHR compared to and situated within four specific concepts. Differential aspects that remain within the ESHR visual circle are included ESHR considerations, those outside the visual ESHR circle are not. The yellow section indicates societal or human realities considerations. There are two areas in Fig. 3 with a black border, farmer capability and adjusting understanding of profitable production, they are crucial areas not consistently or specifically considered in any of the socio-ecological concepts but are encouraged by the ESHR.

consistency in detailed considerations, and improve practice, see section "Ecological considerations relevant to the ESHR" for general explanations, and sections "ESHR specific to the coffee farming landscape context", "Examples of intertwined ESHR considerations for functionally biodiverse coffee farming landscapes" for explanations specific to the coffee farming landscape.

Consistency in sensitivity to ecological considerations within contextual human realities, as they vary across different agricultural systems and landscapes and over time, is encouraged by recognising (i) independence and reciprocity of and between the two aspects of the concept, see sections "Intertwined intangible and tangible realities" and "Examples of intertwined ESHR considerations for functionally biodiverse coffee farming landscapes". And (ii) variability in each of the two aspects of the concept by landscape context, see Table 2 and section "Examples of intertwined ESHR considerations for functionally biodiverse coffee farming landscapes".

Functional biodiversity. Functional biodiversity is the ESHR objective. ESHR agricultural systems and landscapes maintain productivity and comprehensive long-term biodiversity outcomes, with emphasis on functional biodiversity that provisions maintained productivity and natural system regulation. The four tiers of rationale for emphasising functional biodiversity for agricultural systems and landscapes are (1) Maintained agricultural productivity while disregarding environmental outcomes; (2) Ranging definitions of the acceptable biodiverse agricultural system, see supplement s3; (3) Inconsistent integration of ecological considerations at system and landscape levels to ensure functional biodiversity for sustained agricultural systems and landscapes; (4) The increasing number of comparisons between agricultural systems that rely on organic or external synthetic inputs (Letourneau and Bothwell, 2008; Shennan et al., 2017) has not resulted in comprehensive use of organic techniques (Vogt and Englund, 2019), and while organic techniques encourage natural system function, they are not synonymous with biodiverse agricultural systems (Vogt, 2019a). Neither of the four tiers are consistently considered when intending to improve functional biodiversity outcomes in agricultural systems or landscapes, noticed during fieldwork in both countries and in literature (Lanz et al., 2018; Vogt and Englund, 2019; Vogt, 2019a, b, c, d).

Functional biodiversity, as reliant on and integral to ecological integrity instead of being an aspect of ecological conditions (Leopold, 1939; Ruzicka and Misovicova, 2009), can naturally ensure or complement the function of a biodiverse agricultural system, including how a system and landscape self-sustains and maintains productivity. An agricultural systems' ability to function including self-sustain over a long period of time is of commercial, social and environmental significance. The intended and eventual function, multi-faceted or only commercial influences whether an outcome is positive and how comprehensively against the three types of significance.

Ecological sensitivity. While ecological knowledge is considered critical for agricultural system stability (Bullock et al., 2017) in practice biodiversity or sustainability outcomes within agricultural systems and landscapes are not synonymous with ideas of ecological integrity (Pe'er et al., 2016). Ecological conditions do however provide the foundation for functional and stable agri-biodiverse systems and landscapes (Leopold, 1939; Bohn and Amundsen, 2004; Weiner, 2017) with minimal need for external and artificial support. For example, functional structure and heterogeneity (Vogt and Englund, 2019) can promote 


\section{Table 4 Brief explanation of the selected concepts.}

Social-

ecological niches

Sustainable

intensification

Ecological

intensification

Ecosystem services

Landscape ecology

Biodiversity

Societal

considerations
Socio-ecological niches (Oijem et al., 2011) attend to agricultural systems within the specific system or community contexts. Consideration of social and ecological conditions is considered equally were introducing new techniques and agricultural technologies with extended opportunity for interpretation within each category, and limited specificity.

While considered ill-defined (Peterson and Snapp, 2015) sustainable intensification promotes conservation of natural habitats through intensive production within existing agricultural patches. Negative environmental influences should reduce while yields increase.

Promotes biodiversity through agricultural patches using varying management practices. Tittonell (2014) explains that ecological intensification uses the natural functionalities that ecosystems offer to create multifunctional agri-ecosystems that are both sustained by nature and sustainable in nature. Kovacs-Hostyanszki et al. (2017) consider ecological intensification a strong alternative to conventional agricultural systems by promoting biodiversity through agricultural production areas using varying management practices. It can also be a significant mitigating factor for damage caused by conventional agricultural land use and practices (Kovacs-Hostyanski et al., 2017). In addition, the ecological intensification may not cater to the productive intentions or needs of all agricultural systems.

Increasing understanding of the value of ecological conditions within a system for varying stakeholders, often translated into monetary value according to the 'service' such conditions provide (Daily et al., 2000; Brown et al., 2007).

The state of the art of landscape ecology was described according to seven principles in 1986 (Forman and Godron, 1986). Risser (1987) identified five main challenges in describing the state of the art and progress in understanding these principles by organising them into four groups as described by Forman (1995). Since then, landscape ecology principles, groups and categories are explained, described and organised in a variety of ways internationally with the seven principles still forming a significant basis. For example, Ruzicka and Misovicova (2009) summarise landscape ecology principles in seven spheres, including a combination of the seven principles from Forman and Godron (1986) and the challenges identified by Risser (1987).

First appearing in the publication in 1988, biodiversity (Wilson, 1988) was to become a concept that overtook wilderness and other terms that sought to describe the natural environment. Defining biodiversity within natural resource management was still in progress in the 1990s (DeLong Jr., 1996; Takacs, 1996). In 2004, Bohn and Amundsen argued that where environmental changes reduce the number of species, it is not just the list of present organisms that changes, but unique interactions that may be lost forever alongside the potential for a new diversity of life. It is a salient point considered missed by the most prominent institutions dedicated to the preservation of biodiversity. By 2006, Holt (2006) revealed different definitions of biodiversity between disciplines and within the discipline of ecology. Since, attempts have been made in various ways to understand, define and categorise biodiversity for conservation purposes (Davis, 2003; Scholes et al., 2005; Cerda and Bidgeain, 2018; Howard et al., 2018). The relevance of ecological considerations (Bohn and Amundsen, 2004) for functional biodiversity, whether it is part of a landscape ecology or an objective for landscape ecology has not been well established with reference to biodiversity being part of landscape ecology (Ruzicka and Misovicova, 2009), and biodiversity being an outcome of landscape ecology through ecological interactions and processes (Leopold, 1939).

The selected concepts are primarily environmental with the exception of sustainability and socio-ecological niches. Societal considerations are either secondary or variably considered and comprehensive. Examples of human realities considered by the ESHR are presented in yellow. Their position is indicative of how each concept considers them and is dynamic depending on how each concept is implemented. Some may not be consistently or obviously considered and the definition used is influential.

See s6, Supplementary information, for an explanation of societal and ecological concepts and pairings. It is recognised that the use of each concept, general or specific in practice might be different from what is in literature.

natural measures for pest and disease control, maintaining system function, including productivity, with minimal to no external synthetic inputs (Florez and Hernandez, 1981; Vandermeer et al., 2014; Hindorf and Ormondi, 2011; Jaramillo et al., 2013; Karungi et al., 2015). Where changing system structure is not possible, biological control may be introduced with significant ecological considerations (Knudsen and Dandurand, 2014; Barratt et al., 2018) to ensure functionally biodiverse systems. Emphasising ecological conditions as significantly influential to functional biodiversity, therefore, seeks to ensure adequate and consistent consideration conducive to functionally biodiverse as opposed to simply biodiverse agricultural systems, Section "Ecological considerations relevant to the ESHR" explains the details of the ecological considerations relevant for the ESHR concept. Section "ESHR specific to the coffee farming landscape context" explains these considerations specific to coffee farming landscapes.

Sensitivity and human realities. Including human realities as an aspect of the concept is an example of how grounded ethnography allows a concept to gradually develop. Initially ecological sensitivity was the extent of the concept, from 2014-2015. After continual reflection, literature review and triangulation, the influences on human interactions and how ecological and conservation science adequately consider human aspects of conservation in the agricultural context became significant considerations. Explicit consideration of the human interaction was determined necessary.

Capability was the most obvious aspect of the human condition influential to outcomes, as included in the six observations from fieldwork. The more advanced considerations were in the less obvious barriers to changing human interactions for improved functional biodiversity outcomes, based on interests and opinions rather than or reliant on a definite situation or capability, including how to improve capability. The advanced considerations, as well as the obvious, are also relevant to external factor influence, and the consideration of stakeholder influence. Extending the human realities consideration past those interacting directly with the natural environment and recognising the significance of human influence despite any relevant advances in conservation, biodiversity or ecological science.

Section "Human realities considerations relevant to the ESHR" explains the details of the human realities aspect of the ESHR concept, including the importance of shaping sensitive human interactions with the natural environment, and section "ESHR specific to the coffee farming landscape context" explains detail for the coffee farming landscape context. 


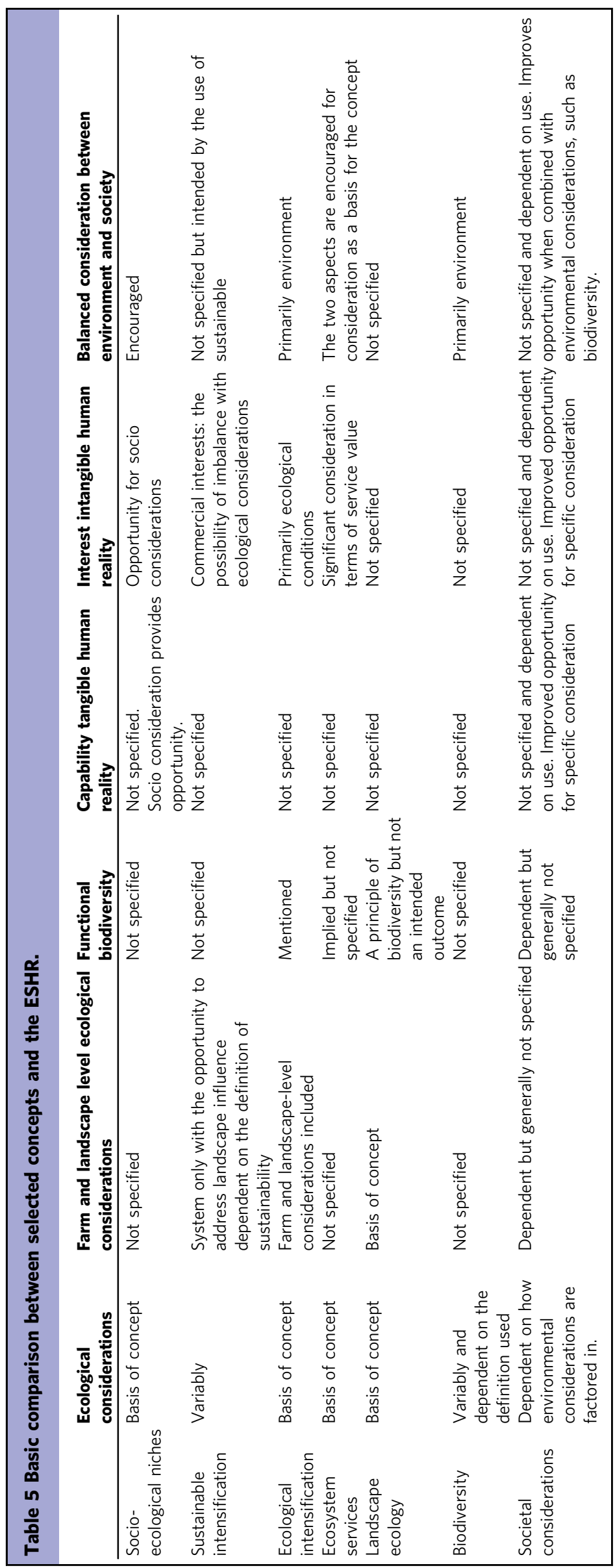


Sensitivity as prevention and resilience literature. While not included in Fig. 3 the sensitivity aspect of the concept provides a novelty from resilience literature and theory that often consider ecological and societal considerations. Resilience literature and theories seek to address adaptive capacity and tend to be relevant most for expectations of difficult conditions (Vogt and Englund, 2019 , p. 67). Sensitivity of human interactions, as a specific point, differentiates from resilience theory and frameworks. The sensitivity of interactions are within human control and can become a preventative measure, as well as a method for system and landscape resilience building. The ESHR seeks to reduce the need for adaptive capacity of productive agricultural systems that result from negative pressures through human influence and interaction. Natural external pressures are not within this type of direct human control. Adaptive capacity and ecological robustness or resilience (Holling, 1973; Gunderson, 2000) of productive natural resource systems, therefore, remain relevant and necessary based on different contextual situations (Vogt and Englund, 2019, p. 67). Being ecologically sensitive within human realities could also be considered a specific resilience strategy, or to reduce the need for resilience from damaging human interactions.

\section{Ecological considerations relevant to the ESHR}

Farm and landscape ecological interactions and processes. The idea of an ecosystem and ecology is often attributed to the early work of Odum (1970), whose studies and publications range from the 1950s. The idea of an ecosystem can easily translate to an agricultural system but remains limited as farm systems are often part of a landscape of connected or disjointed farm systems. The focal point for the ESHR is farm or agricultural systems that form patches or land use categories within a landscape, often part of many agricultural systems that form the landscape configuration. The ESHR ensures an understanding that ecological interactions and processes of an agricultural system are not contained to that one system. They are influenced by and influence varying spatial distributions and densities across an agricultural landscape, most often described as part of landscape ecology (Forman and Godron, 1986; Risser, 1987; Forman, 1995; Ruzicka and Misovicova, 2009), see discussion for explanations of landscape ecology.

Just as farm-level ecological conditions are related to landscape ecological conditions, landscape ecological conditions are related to farm-level conditions. They are interdependent in varying directions including vertical and horizontal; below and above ground; and system, or landscape patch and neighbouring landscape (Brown and Gange, 2002; Scheu and Setala, 2002; Kleijn et al, 2018; Vogt, 2019a). The system and landscape interdependence can in part be influenced by spillover, complementary to the idea of dynamic rather than static landscape ecological conditions.

Spillover encourages an understanding of how a system within a landscape, a landscaped patch, influences the neighbouring landscapes, and vice versa. Negative or positive spillover can reach neighbouring and distanced natural systems. For example, run-off and leaching can significantly impact not only terrestrial but also aquatic neighbouring and distant areas (Boutin and Jobin, 1998; Galdeano-Gomez et al., 2008; Larsen et al., 2017a; Quinteros et al., 2017; Boudh and Singh, 2019) with human health implications.

Movement ecology (Jeltsch et al., 2013) progresses the idea of dynamic conditions of landscape ecology and interactions between ecosystems and how spillover can change ecological conditions in landscape patches. For landscapes that include agricultural systems, the idea promotes animal or plant conservation across landscapes (Rodrigues and Chiarello, 2018), between productive and natural landscape patches, and between different production landscapes according to configuration, composition and plant species heterogeneity (Vogt and Englund, 2019). The implications of movement ecology, as with spillover, can be positive and negative, and applicable to vertical and horizontal, above and below ground, and between landscape patch conditions (Vogt, 2019a, p. 4).

Plant and crop ${ }^{2}$ selections for system and landscape ecology. Plant and crop diversity within and across functional groups is a guiding principle for integrating conservation with agricultural production (Fischer et al., 2005; 2017). Seeking increased crop and plant diversity, and farm and landscape heterogeneity selections for a diverse system will influence biodiversity outcomes (Hass et al., 2018), provision ecological (Wilson et al., 2017) and nutritional benefit, and withstand regionally specific climatic variations (Manners and van Etten, 2018). Plant and crop diversity does not always result in improved biodiversity outcomes (Hass et al., 2018), but is beneficial enough to suggest breeding new varieties conducive to productive system function without relying on ecological or natural conditions (Barot et al., 2017). Plant and crop selections as related to access to resources are considered further in sections "ESHR specific to the coffee farming landscape context" and "Examples of intertwined ESHR considerations for functionally biodiverse coffee farming landscapes".

Examples of combined considerations as relevant to the ESHR. Plant and crop selection and landscape ecology considerations are extremely relevant for the ESHR. For example, pollinator plant mutualism represent a community (Russo et al., 2014) and pollinator diversity and abundance is higher in diversified and organic fields, and landscapes of high-quality habitat (Carvalheiro et al., 2013; Lichtenberg et al., 2017) including trees, bushes, crops and varying ground cover. As pollinator abundance and diversity, and pollination versus visitation are dependent on this mutualism, diversified fields of functional crop and plant selections can be positively associated. This is a contrast to conventional monoculture farming and associated maintenance practices. The contrast is not limited to an agricultural system, with landscape implications (Maxim and van der Sluijs, 2013; Kleijn et al., 2015). Degraded and abandoned systems and landscapes are also relevant for this consideration. Biodiversity friendly crops, crops that naturally grow well in forested or biodiverse agricultural systems, such as coffee, could be prioritised to convert degraded and abandoned land (Wilson et al., 2017; Hass et al., 2018). The benefit of growing biodiversity-friendly or standard crops next to intact forest (Oliveira and Estrada, 2017) is however contextualised by landscape ecological implications of species and particularly crop movement into natural areas (Jeltsch et al., 2013). The benefit of neighbouring forested areas for agricultural system function is however also recognised (Toledo et al., 2018). Farm and landscape heterogeneity (Vogt and Englund, 2019) is, therefore, conducive to functional biodiversity outcomes (Lin, 2001; Lichtenberg et al., 2017) when ecological considerations relevant to plant and crop selections are thoroughly and consistently integrated.

Farm design and ecological considerations of the ESHR. Theoretical and conceptual applications of ESHR ecological considerations are explained in Vogt (2019a). The explanations provide association and application of ecological principles with and as used by four farm design approaches or disciplines. They include ecotones and the edge effect, and ecological succession (Vogt, 2019a, Table 2a, b). The practical use of these considerations in farm design and practice provides justification for the ESHR and explains the opportunity provided for improved 
understanding of the complementarity between farm design approaches, with the idea of an opportunity for improved functional biodiversity outcomes.

\section{Human realities considerations relevant to the ESHR}

Human interaction with agricultural systems and landscapes. Agricultural landscapes are ultimately a context of significant human interaction and presence, modifying the environment for productive intention. Schroth and McNeely (2011) suggest urgency in balancing priority setting between biodiversity and society through careful consideration of local needs and aspirations. In 1968 Ostrom argued that common resources were better managed where those benefiting due to close proximity had control (Ostrom, 1990). In this instance, the majority of environmental damage is attributed to the power given to external and distanced groups using resources for personal advantage. Improving biodiversity outcomes in these landscapes requires consideration of human implication and influence not only in terms of needs and aspirations but also in terms of the range of influential stakeholders involved in agricultural landscapes and industries. Distinct realities of stakeholders as individuals or groups interacting with the natural environment for productive outcomes and within the community become more evident. The influence of external and distanced groups can significantly determine how those closest to natural resources prioritise the environment over economic security. It is not however accepted as consistent that those closest to natural resources will maintain more interest in protecting the environment, particularly where using the environment for economic or survival priority. The idea that the negative effects of exploiting natural resources are often most felt by those in closest proximity is accepted however effects on the environment are occasionally invisible until detailed evaluations and observations are made.

Improved understanding of how contrary activities influence the lives of those closest to the natural environment may therefore improve consistency in protection. The variable human values influencing interactions with the natural environment across contexts and time bring attention to heterogeneity within any 'human' or 'society' consideration.

The idea of heterogeneity between and across societal groups and individuals is accepted for the ESHR, alongside power dynamics to encourage necessary change. While 'society' sufficiently encompasses the varying stakeholders involved in agricultural systems and landscapes, individual and group opinions, interests, perspectives and values do vary and are important to understand alongside the consideration of capability, influenced by the intangibles of opinions, interests and perspectives. How they change over time and how they form are also important. For this reason, human realities instead of societal are referred to and used in the ESHR.

Human realities. Heterogeneity of the human aspects of the ESHR is referred to as realities with two aspects, intangible and tangible to ensure detailed consideration of how human realities differ and are influenced. Each stakeholder has its own realities at the group and individual levels, influenced by intangible and tangible components. Intangible is different from tangible and they are interdependent and mutually influential (Vogt, 2019a, p. 9; 2020, pp. 6-7).

- Tangible human realities explain the more visible or obvious elements that influence whether more biodiverse agricultural systems can be realized. They are extremely important for ensuring long-term functional biodiversity outcomes and are influenced by and influential to intangible human realities, particularly understanding of or experience with harvest implication and maintenance requirements. They include capability; access to resources and other factors that negate or override an interest or need for more biodiverse systems. Capability can determine how the function and complexity of ecological interactions and processes within an agri-biodiverse system are influenced by human interactions according to modification through land use allocations, design and maintenance. Specificity in consideration can ensure detail and consistency, improving understanding.

- Intangible human realities can include interest and perception, influenced by many factors including definitions of realities used. They are less or not visible and equally if not more influential. Where believed for a length of time at a consensus group level they can become considered a form of reality. The more tangible realities, perceptible by touch or sight rather than less visible intangible realities formed by societal or individual preference or opinion, is an additional human reality the concept draws attention to. Tangible human realities can include existing or required access to resources and capability to create and maintain more biodiverse systems, with potential influence on intangible realities, and vice versa.

Intertwined intangible and tangible realities. The influence of intangible human realities in improving or addressing tangible realities are recognised, as is the influence of tangible realities on intangible realities. For example, improving interest increases the chance of increases in capability; and increasing capability increases the chance of interest; or, the landscape context and capability allowed by generational existing knowledge and practices, and influence on interest (Vogt, 2021, supplement A).

Understanding and assessing human realities using the ESHR. The methodology and method used to understand contextual human realities will ultimately determine ESHR assessment, implementation and outcomes, and evaluation of outcomes. There are several social science methods and methodology that might be used. The landscape context and accessibility, detail sought and resources available will assist to determine the appropriate combination of methods and methodology used. Subsequently, determining the detail and accuracy, by representation and depth of information collected, of any assessment, and of eventual understanding and practice.

Farm design and human realities of the ESHR. Theoretical and conceptual applications of the human realities considerations of the ESHR are explained in Vogt (2019a). The explanations provide association and application of human realities principles used by four farm design approaches or disciplines. They include, design and capability for long-term function and maintenance provided by zones, and functional design, and ecological harvest effect (Vogt, 2019a, see Table 3a, b). The practical use of these considerations for farm design and practice demonstrates how human realities considerations are already used and how they can optimize the function of a biodiverse agricultural system and landscape. The ESHR provides an opportunity for increased understanding of the complementarity between farm design approaches and of the contribution of farm design for human realities considerations, with the idea of opportunity for improved implementation, practice and functional biodiversity outcomes.

ESHR for functional biodiversity. There is significant scope for productive agricultural systems that disregard environmental and more specifically biodiversity outcomes, or biodiverse agricultural 
landscapes that allow crop yield without functional ecological interactions and processes. Relying on ecological conditions can improve productive function and stability across varying types of system and landscape complexity (Vogt, 2019a; Vogt and Englund, 2019). Adjusting realities through improved understanding and promoting changes is expected to improve functional biodiversity.

\section{ESHR specific to the coffee farming landscape context}

Background. Coffee farming landscapes are typically found between the Tropic of Capricorn and Cancer, $23.437^{\circ}$ north and south of the equator, and the biotic and abiotic composition of these landscapes is similar. The countries are often developing or emerging economies. The landscapes are often significantly modified and simplified through human interactions and located in developing countries, with common experiences of multidimensional poverty (Vogt, 2019b), including environmental degradation and being subject to international trade dynamics. Most often traded as a cash crop coffee can represent above $10 \%$ of a countries' total export value (ITC, 2011) and is therefore relied on for export and foreign exchange reasons. The reliance can then influence interactions with the natural environment according to a yield quantity prioritization, market and buyer preferences or local land distribution policies or preferences. Intensification of farming within smaller land sizes has also provisioned high yield quantity, Costa Rica is an example (FAOStat, 2011). As coffee is most consumed in developed and emerging economy countries (ICO, 2018; Vogt, 2019a), the coffee industry inevitably involves power dynamics through sourcing chains that span multiple countries, and include developing and developed world dynamics. Commercial aspects of the industry and associated power dynamics can result in corruption, policy complications and irresponsible corporate activities (Babbar and Zak, 1995; Jha et al., 2014). Sustainability or biodiversity interests are therefore amongst a range of contextual layers that influence resulting practices in coffee farming landscapes. These interests may be balanced or some may dominate. Ensuring sufficient income from productive landscapes can reduce interest in conservation and biodiversity directly influencing the physical composition of a landscape, and subsequent environmental and societal outcomes.

Ecological considerations of coffee farms and landscapes. System and landscape composition, and plant and crop heterogeneity determine how shade and ground cover contribute to a productive system through functional biodiversity outcomes (Vogt and Englund, 2019; Vogt, 2019a). Improved biodiversity outcomes through more crop and plant diverse agricultural systems and landscapes, for markets or subsistence benefit, are encouraged by a functional complexity conducive to sustained productivity. The visual representation of the varying shade and ground cover structures and functions of a coffee farm (see s5 and Fig. s5.1, Supplementary information), shows how groundcover heterogeneity can vary within shaded coffee systems with maintained functional biodiversity outcomes. Options for shade and ground cover structure and function are diverse, influenced by plant and crop variety inclusion and spatial distributions. The ecological dynamics of different shade and ground cover systems, despite a disproportionate number of interactions, are not isolated. High levels of interdependence for system biodiversity and ecological outcomes (Sepulveda and Carrillo, 2015; Vogt, 2019a), and above and below ground interactions (Brown and Gange, 2002; Scheu and Setala, 2002), particularly where human maintenance and harvest considerations are included (Vogt, 2019a; see s5 and Fig. s5.2, Supplementary information) are considered.
For the coffee farm and landscape context, the contribution of shade or groundcover for coffee system and landscape function and biodiversity outcomes is conditioned by plant and crop heterogeneity, functional structure and complexity of a system. Crop and plant variety selections and spatial distributions assist to create functional ecological interactions and processes conducive for productive, functional biodiversity in coffee farms and landscapes. System and landscape function is an integrated consideration, relevant not only to ecological conditions but also to human realities through implementation (Vogt, 2020, 2021).

Human realities of coffee farming landscapes (see Tables 1 and 2 for detailed explanations). Human realities are not institutionally bound, allowing for and accepting the significant influence individual realities can have on group realities and responses. These realities are stakeholder and contextually reliant but also circumstantial dependent on different situations providing additional human realities contexts within which biodiverse agricultural systems might be created and/or maintained. The consideration is consistent and relevant to all stakeholders but most examples provided here are related to farmer reality, recognising how external factors might influence the control farmers to have on their farm and in a farming landscape.

Human realities for coffee farming systems and landscapes are explained across two levels as relevant to intangible and tangible realities; (i) Common human realities for all coffee farming systems and landscapes; and (ii) Varying human realities, as influenced by landscape and country context, and relevant to the direct influence of farmers. The in-between allows for the influence of other stakeholders, societal groups and individuals that might influence farmer human realities.

i. Common human realities explained as within farmer control, organised according to intangible and tangible human realities. Farmers might be considered significant gatekeepers for change. Their approach to managing their farm will often be guided by the personal opinion of best outcomes within the parameters of the above described and other dynamics. As a cooperative member, they might learn of farming practices from the cooperative, or members of. When a member or not a member, they might learn from trial and error, community members that are farmers, other extension efforts, or from international connections. It may not immediately influence eventual practices however their opinion may be influenced through continual and in-depth interactions and information sharing. The intangible is summarised as interest influenced by (i) Productivity: yield and biodiversity; (ii) Aesthetics, maintenance and harvest preferences. The tangible include (i) Access to resources; (ii) Capability.

ii. Varying human realities explained as beyond farmer control recognises macro factors often determined at a landscape, country or regional level. Two examples of differing human realities within active coffee farming landscapes of Cuba and Costa Rica are (1) Interactions with the international market-intangible and tangible realities; and (2) Access to crop and plant varietiestangible realities.

Direct interactions with the international market can be optional with restrictions based on intangible and tangible human realities including: historic situations related to capability, opportunity, or government regulation, and then interest and preference. It is not therefore always the situation that interaction with the international market is absolutely beyond farmer control but it can be the case and significant consideration. 
The implications of beyond farmer control considerations for functional biodiversity outcomes refer firstly, to the influence farmers have over managing international market demands. Secondly, options available for diversifying a farm system.

Improved understanding of human realities, is not expected to result in an absolute increase in interest in more biodiverse systems. Nor ensure more diversity in crops, plants or trees, of a functionally biodiverse system. It may however ensure that all systems are functional while maintaining productive intentions. It may also ensure understanding that spatial distribution of functionally biodiverse systems across a landscape while maintaining productivity is possible. An additional consideration within human realities according to stakeholders is that increased control for a farmer is not synonymous with an improved biodiversity outcome (Batari et al., 2017). An interest (intangible human reality) and capability (tangible human reality) to maintain or improve biodiversity outcomes is ultimately relevant for all stakeholders as all have their own influence, direct or indirect on outcomes. See 'the in between' in Table 1 .

\section{Examples of intertwined ESHR considerations for functionally biodiverse coffee farming landscapes}

ESHR and conceptual understandings of coffee quality and market value. The functional biodiversity considerations relevant to yield quality and quantity (Vogt, 2020) provide a concise example of how human realities and ecological considerations are inevitably intertwined for improved functional biodiversity outcomes, bringing fieldwork observations and reflections, and the narrative review together. Yield quality and quantity as measures of system and landscape productivity are explained as relevant to human realities in Table 1 . Yield quality can increase with functional ecological conditions evenly distributed across a farm and landscape or from context-appropriate ecological bundles within a crop production system (Bommarco, 2012; Klatt et al., 2014; Bartley et al., 2013). Contributing traits for yield quality include pollination service and pest and disease control toward which functional biodiversity significantly contributes. Pollinator abundance and diversity, and subsequent pollination improves tree health, fruit set, and yield quality (Vergara and Badano, 2009). The expected decrease in crop density would, in most cases, see a balanced or maintained reduction in yield quantity for more biodiverse systems, with the opportunity for yield quality increases.

Co-occurring pests and diseases represent some of the more challenging situations (Caicedo et al., 2013; Vandermeer et al., 2014) for coffee systems and landscapes. Even one pest or disease type can cause significant damage and influence yield quantity and quality. The reach of pest and disease outbreaks across coffee farming landscapes is an indication of system dysfunction and imbalance (Toniutti et al., 2017; Larsen and Noack, 2017b). How ecological conditions are understood as influential to preventing these conditions has a productivity implication. Improved tree health, system stability and function based on balanced ecological conditions can improve a systems ability to resist or control various pests and diseases (Florez and Hernandez, 1981; Vandermeer et al., 2014; Hindorf and Ormondi, 2011; Jaramillo et al., 2013; Karungi et al., 2015), ensuring system function and productivity by yield quantity and quality.

A conceptual ESHR assessment of coffee quality indicators valued by three coffee market types: conventional, specialty and sustainable, outlines the positive and negotiate associations with functional biodiversity and how these indicators are currently valued by the different market types (Vogt, 2020, p. 3). The ESHR provides an opportunity to separate understandings of the association according to ecological considerations and human realities to eventually understand in detail how functional biodiversity can improve the market value of coffee (pp. 5-8). The conceptual assessment identifies detailed existing barriers to increases in functionally biodiverse coffee farms and landscapes according to the different market types, with recommendations for future assessment and practice to remove these barriers (pp. 10-11).

Farm design, and ESHR considerations for coffee farming landscapes. The conceptual application of ecological considerations, edge effect, ecotones and ecological succession at system and landscape level, and of human realities: human visitation and management; human presence in the system and landscape; human health; and ecological harvest by farm design approaches are explained specifically to coffee farming landscapes. They are ultimately integrated considerations but might not be given proportional attention in the design process or in implementation and maintenance. These specific considerations for the coffee farming landscape context are explained in Table 4a, b in Vogt (2019a). With ESHR integrated considerations as estimates of influence on yield and required changes in management practices provided visually (see Fig. s5.2, Supplementary information). The ESHR provides an opportunity for increased understanding of the complementarity between farm design approaches, with the idea of an opportunity for improved detail in assessment, design, implementation and practice for improved functional biodiversity outcomes. Identifying complementarity and using the understanding for assessment and practice is only part of a comprehensive ESHR approach. Details omitted from farm design approaches that the ESHR brings attention to include: generational and organic techniques, and details of the integration of genetically modified crops (Vogt, 2019a, pp. 6-7; p. 13).

Examples of ESHR aligned options for coffee systems. Shade and ground-cover structure categories in Fig. 5.2, Supplementary information, provide ESHR aligned visual and theoretical representations of how biodiversity within coffee systems can vary. It is explained according to estimations of crop density, quality and quantity of yield and human management implications (Vogt, 2019a) demonstrating how biodiverse coffee systems accommodate varying human realities.

Figures 1 and 2 below provide photo images of active farms observed during fieldwork, one from each study country. They are selected as representative of the different biodiverse systems. The two systems produce for market sale however the capability and knowledge set to manage each system is distinct. The visual representations indicate two types of biodiversity on a farm and how the different types of biodiversity might have human realities implication including; human movement through the system with maintenance and harvest implication, complementary to Fig. s5.2, Supplementary information. They also demonstrate how aesthetic preferences might influence interest in more biodiverse coffee systems. Outputs from each system are also quite distinct, see Table 3 for more information. How interest might change with an improved understanding of ESHR aligned biodiverse system and landscape implications can be determined with further study.

\section{Discussion}

Coffee and other agricultural systems are natural systems that have been modified and simplified for ease of management (Western, 2001) and agricultural productivity. Attitudes toward simplification are influenced by personal views and judgments of the negative and positive influences of human actions (Redman, 1999). Understandings of choice and constraint (Walmsley and 
Lewis, 1984; 1993) may further influence human actions. Where productive intentions dominate, the choice to improve environmental outcomes may feel constrained at varying levels. As interests between influencing stakeholders compete or contrast, the potential to shift interactions with the natural environment may become more possible or constrained. Concepts often clarify intentions in a simple and straightforward manner. Sometimes concepts become paradigms with wide-reaching use and influence (Luckett, 2004; Dunlap, 2010; Cohen, 2015). Finding the right balance between detail and simplicity of a concept (Johnson and Lidstrom, 2018), while allowing for different contextual uses is important. Particularly in landscapes of myriad interests where intention for aligned outcomes can easily skew toward productivity at environmental and societal cost. A detailed enough can allow for integration and implementation of advanced knowledge sets for human interactions with the natural environment that can better inform stakeholders.

The importance of ecological interactions and processes for biodiverse agricultural systems and landscapes (Leopold, 1939) has long been understood, and socio-ecological theories have set the foundation for bringing ecological and societal considerations together. Ecological conditions are implicitly and variably considered for agri-biodiverse systems, and drawing attention to them is not novel. Ensuring consistent consideration of human realities is also an implicit consideration. Encouraging consistency of these considerations and then in the detail of each is important and not necessarily occurring. A well-developed concept can be effective in encouraging such consistent consideration and influence.

The ESHR intends to improve understanding of the value of functional biodiversity within agricultural systems and landscapes with well-integrated basal considerations of ecological interactions and processes at system and landscape level, and intangible and tangible human realities as contextual and variable across stakeholders and over time. How the ESHR compares to existing similar concepts is explained to justify novelty and contribution. Basic and detailed concept clarifications are provided and comparisons with and against the ESHR are provided.

ESHR leverage through conceptual clarifications. Table 4 provides brief explanations of selected concepts that are similar to or included in the ESHR. Each concept is specifically similar, rather than general concepts like sustainability, they were selected for comparison after the ESHR was developed. Figure 3 conceptually situates and compares four of the specific concepts with the ESHR demonstrating how the ESHR provides a slightly distinct approach, with potential for improved functional biodiversity outcomes. The four concepts in Fig. 3 are not included in the ESHR. Landscape ecology and biodiversity are included in the ESHR and are therefore explained in Tables 4 and 5 with written rather than visual comparisons provided. Societal considerations are included in Tables 4 and 5 and in Fig. 3. They are not considered as a concept instead of as a topic for inclusion and necessary consideration.

Brief explanations of all compared concepts. Table 4 provides an explanation of each selected concept. See s6, Supplementary information for further information about societal and ecological concepts and considerations.

Situating and comparing the ESHR with four specific concepts. The ESHR provides an opportunity for improved specificity in ecological and human realities considerations, toward the objective of functional biodiversity. As a guiding concept, it provides an opportunity to integrate these more specific concepts and can encourage a compromise between them complementary to the ESHR. The compromise and complementarity are expected to improve functional biodiversity outcomes in agricultural landscapes. The improved specificity allows the opportunity for understanding complementarity and provisions foundational detail for implementation and secured outcome considerations. These considerations are relevant for individual and or institutional implementation approaches and mechanisms.

Basic conceptual clarifications. Figure 3 provides visually represented basic conceptual comparisons with the ESHR, including specific societal considerations. Table 4 provides a summarised comparison of the four concepts included in Fig. 3, and of landscape ecology, biodiversity and societal considerations against the ESHR.

Detailed conceptual clarifications. A comparison between the ESHR and the six selected concepts is explained in more detail in the following section. Firstly, according to ecological conditions and then human realities to explain improved specificity allowed by the ESHR.

ESHR, functional biodiversity and ecological conditions. The ESHR works toward functional biodiversity outcomes, providing additional classification for commonly used definitions of biodiversity. Increased specificity provided with 'function' and then with the two aspects of the concept can encourage accurate understanding of positive biodiversity outcomes and limit the opportunity to interpret or select any definition. 'Functional ensures consideration of ecological conditions, the interactions that influence how and why species are 'valuable' or provide function within environmental, and productive, terms, and of human realities considerations. While the concepts in Fig. 3 might use biodiversity as a positive indicator, the definition used is allowed to vary somewhat. In addition, where biodiversity is used as a guiding concept there can be variance in what is sought and how it will be worked toward. For example, biodiversity might not naturally resolve system damage caused by pests and disease but adequate integration of ecological conditions and science that considers individual system and landscape level needs and ensured functional biodiversity could improve system function including sustained production. See explanation of landscape ecology and biodiversity.

All concepts in Fig. 3 consider ecological conditions, with the exception of sustainable intensification and societal considerations. Consideration of spatial levels of ecological conditions is however variable, with system level most considered, reducing consistent understanding of consideration of landscape outcomes and influence and interaction between system and landscape level conditions.

Sustainable intensification does not explicitly and certainly variably includes these considerations while encouraging complementary techniques. It seeks to encourage intensive agricultural patches and more biodiversity in neighbouring landscape patches, relevant to considerations of spatial levels. While not contrary to what the ESHR encourages, the ESHR specifically encourages functional biodiversity in and across all landscape patches.

Societal considerations do not consistently consider biodiversity or the details of what biodiversity is.

Ecological intensification, ecosystem services and socio-ecological niches find foundation in ecological science, they might not however adequately address the ecological basis for functional biodiversity. Ecosystem services can also bring attention to value rather than function for human realities considerations with 
possible implication for encouraged and resulting ecological conditions, explained in more detail in the following subsection "ESHR and human realities considerations". If the compared concepts in Fig. 3 use landscape ecology considerations there is an opportunity to overlook each or every principle as the definition and concept continue to change and can differ between countries.

Landscape ecology is included as a compared concept in Tables 4 and 5 as specifically relevant to section "Farm and landscape ecological interactions and processes". From earlier conceptualizing (Forman and Godron, 1986; Risser, 1987; Forman, 1995), the most relevant principles for landscape ecological interactions and processes included in the ESHR for the agricultural context are; interactions between ecosystems (p. 136), and relevant to the details of farm design; patch, corridor, matrix (p. 135). More recent advances in understanding and conceptualising landscape ecology (Ruzicka and Misovicova, 2009) as relevant to the ESHR include: structure and function; the flow of organism species; redistribution of nutrients; and flow of energy, and structure and function.

There is also the difference of making biodiversity, or functional biodiversity, an objective compared to an integrated consideration. A significant difference between landscape ecology and the ESHR is the categorisation of biodiversity as a sphere of landscape ecology. By comparison, the ESHR intends for biodiversity to be an outcome dependent on functional systems and landscape ecology (Leopold, 1939), making functional biodiversity the objective rather than a principle or part of what landscape ecology is. The ESHR also intends to emphasize the interaction or interdependence within and between system and landscape conditions.

Biodiversity as explained in the results section has varying definitions, and for agricultural systems, the function is not always assured. Emphasising biodiversity as a concept encourages an understanding of objective rather than an aspect of system or landscape ecology, an ESHR aligned understanding. The emphasis on the function of ecological conditions for functional biodiversity is not explicitly required or explained for all concepts. The ESHR, therefore, ensures consistency in functional ecological conditions for functional biodiversity outcomes at the system and landscape-level complementary to continued use of any of these concepts with improved specificity and long-term maintained functional biodiversity outcomes.

ESHR and human realities considerations. The ESHR uses human realities to encapsulate the numerous stakeholders involved in agricultural systems and landscapes and ensures consideration of their perspectives and opinions and the difference between opinions and perspectives within stakeholder groups. The ESHR can make the different perspectives and opinions more obvious for improved understanding.

Human realities can be circumstantial and can determine how any ESHR intervention or approach will improve functional biodiversity outcomes in coffee farming landscapes. The intangible and tangible of these realities are emphasised to ensure understanding that the two types of realities are interdependent, and that outcomes rely on several human factors including interest, and capability and access to resources. These considerations are given limited consistent attention by the concepts considered.

Each concept is geared to address an assumed understanding of human-natural environment interactions. Those that seek to address societal considerations are limited to the detail allowed with variable definite consideration included in Fig. 3, yellow. Table 4 provides a summarised explanation. Regarding the productive premise for natural resource systems in agricultural systems and landscapes, each concept considers societal outcomes, and other 'less important' or non-valuable ecological aspects variably. The specifics of each concept and how human realities can add detail or improve the application and use of any one of the concepts are provided.

Biodiversity does not explicitly ensure or encourage societal consideration and certainly not of human realities consistently. The functional aspect of biodiversity encouraged by the ESHR integrates human realities considerations.

Socio-ecological niches encourage consideration of local context, and the human realities considerations can provide more specificity for these local considerations.

Sustainable and ecological intensification human realities encourage a compromise between the two concepts through a consistent understanding of contextual appropriateness of density of biodiversity within agricultural patches. The contextual appropriateness is influenced by stakeholder interest and capability to create and maintain the productivity of commercial crops versus using ESHR aligned functionally biodiverse agricultural systems that maintain productivity.

Ecosystem services are geared toward increasing interest in more biodiverse and ecologically sound production systems, and conservation of natural systems through a service understanding. It provides an additional 'selling point' for the intangible human realities of economic and environmental interest for varying stakeholders by emphasising the value of ecological conditions in monetary and other service terms. There are two areas of ecosystem services that the ESHR provides improved specificity for (1) While well aligned and useful, the idea of the environment servicing humans accommodates existing understanding and premise that the environment should be 'used' by humans. Eventually, understanding can lead to an idea of reciprocity between humans and the environment, however, the power dynamic of human dominance remains and could fundamentally shift to better accommodate socio-ecological rather than only ecological theories for few societal considerations. Some ecological interactions and processes do not offer obvious 'value' yet remain essential for system function (Small et al., 2017); others associate positively with market value but are yet to be well understood (Vogt, 2019c), black border in Fig. 3 adjusting understanding of profitable production'. (2) Ecosystem services provide little explicit consideration of how more biodiverse systems should be developed or maintained, included in societal considerations of Fig. 3, with a black border, farmer capability. Without specificity, there is a great opportunity to conduct work 'in the name of ecosystem services' with an emphasis on value rather than an ensured system function, and without eventual alignment of or maintained outcomes through implementation.

Summary The ESHR encourages consistent understanding of reciprocity between humans and the environment rather than how a more functionally biodiverse system can serve our needs, or represent or become valuable with emphasis on balance between productive intentions and ecological conditions at the system and landscape level. Any intensification of sustainability or ecological agriculture becomes relevant to a system and landscape, leading to a landscape balance in functional biodiversity, with variable intensification but consistent functional biodiversity in any landscape patch. The balance emphasised is function value-based, a part of which is economic and service value. The tangible human reality of capability encourages consistent consideration for implementation to ensure longterm and maintained outcomes, an important detail that is often not included in any of the concepts considered. It also ensures understanding of a specific concept objective or aim, functionally biodiverse agricultural systems and landscapes, to ensure human realities of all stakeholders are well-considered alongside the ecological aspects of functional biodiversity. The specific concept 
objective also assists in understanding why sensitivity is necessary. See rationale for sensitivity in sections "Ecological" sensitivity" and "Sensitivity as prevention and resilience literature".

\section{Conclusion and opportunities for future use}

Novelty of the ESHR concept is in (1) Understanding that sensitivity to ecological conditions is within the control of human interactions; (2) Understanding human realities, according to intangible and tangible aspects as a significant if not the most significant influencing factor; (3) Understanding reciprocal benefit of ecological conditions for human realities, including and specifically the human reality of maintained commercial production; (4) Considering functional biodiversity as an objective reliant on ecological interactions and processes at farm and landscape spatial levels, rather than as part of a system and/or landscape ecology (5) Considering spatial scales of ecological interactions and processes rather than limiting consideration to a system-level; (6) Allowing for changes in a system conducive to improved functional biodiversity for prevention or as a resilience strategy, rather than relying on system or landscape resilience to contrary external human pressures (Holling, 1973); (7) Encouraging consistency in these considerations through human natural environment interactions.

As a conceptual article, the presented considerations provide guidance for assessments, planned responses and implementation toward improved functional biodiversity outcomes in agricultural systems and landscapes. The human realities aspect of the concept encourages understanding at a contextual, individual and group level for farmers (and other stakeholders) to ensure uptake and effective implementation. Also integrated are ideas of incentive for all stakeholder groups and landscape uptake based on assured income according to the influence of biodiversity on productivity and yield. These advantages are expected to reduce resistance to change, and increase interest in functionally biodiverse agricultural systems and landscapes. The societal advantage, including economic benefit, will vary according to individual and landscape contextualities, and subsequently so will functional biodiversity outcomes according to landscape circumstance and context. How assured income is calculated can vary and methodological and conceptual variability must be addressed (Vogt, 2020, p. 11). Using clearly defined methodology and methods to accurately determine contextual intangible and tangible human realities, by landscape and farm, and time, is necessary, rather than assuming realities like interest, capability and access to resources are obvious or similar in every landscape; and instead of relying on sight, touch, and more superficial or rapid observations.

The ESHR can improve the detail of existing similar concepts due to the following points: (a) The concept encourages consistent understanding of contextual ecological conditions and human realities for any human natural-environment interaction in agricultural landscapes for more consistent and ambitious functional biodiversity outcomes. (b) System and landscape ecology create functional biodiversity across a landscape as an objective and are reliant on and influenced by human realities. (c) Ensuring adequate attention and investment is given to: intangible and tangible human realities such as capabilities, access to resources, and interest to create or maintain functionally biodiverse coffee systems ensures long-term functional biodiversity rather than contrary or inhibited intentions and outcomes. (d) ESHR aligned interactions encourage consistent sensitivity to system and landscape ecological conditions, and to intangible and tangible human realities, over time and based on individual and group, landscape, and circumstantial contextualities. (e)
Reciprocity between human realities, and functional system and landscape ecological conditions across different types of created or maintained ecological complexity are understood and consistently considered. (f) Contextual human realities, including landscape conditions and circumstance, will significantly influence the preferred type of ecological complexity that forms system and landscape functional biodiversity.

In extreme circumstances ESHR understanding could ensure rapid response that considers implementation and long term benefit, rather than short term solutions. These rapid responses would depend on and improve from preemptive assessments and understandings that use the ESHR. Findings from conceptual applications of the ESHR and ESHR aligned explanations of different biodiverse systems (see Fig 5.1 and 5.2, supplementary information), can improve understanding for future assessments and responses across different coffee farms and landscapes.

Future studies can use the ESHR to (I) Identify how ESHR functional biodiversity in coffee systems and landscapes, newly introduced or generationally biodiverse, addresses various human realities, including long term productive intentions compared to conventional systems in the same landscape to support or verify the ESHR; (II) Determine if improved understanding allowed by the ESHR increases interest and uptake in functionally biodiverse coffee systems and landscapes; (III) Determine if biodiversity outcomes are functional and provision direct value for humans versus indirect via system function; (IV) Improve biodiverse coffee systems that have not provided long term function; (V) Emphasize how being sensitive to ecological conditions within human realities can (i) Improve functional biodiversity outcomes as a preventative and responsive human-based approach; (ii) Decrease need for resilience to human interactions with agricultural systems.

Received: 31 January 2020; Accepted: 7 June 2021; Published online: 02 July 2021

\section{Notes}

1 Reference to system and landscape is used through the manuscript. 'System' is used to clarify an idea of a contained landscape patch, mainly agricultural land use or agricultural system compared to an entire landscape made up of different land use, or landscape patches, different 'systems'. It is recognised that a system can also be used to explain or describe a landscape. The ESHR encourages an understanding of the human aspect, as well as the natural environment or natural resource system at a system and landscape level.

2 Plant and crop are different by a domestication process. Crops are grown for harvest, plants provide a functional purpose in a natural or agricultural system but are not within a system for entirely productive or harvest purposes. Whether they produce something that is harvestable is different. The definition will differ dependent also on the type of agricultural system, conventional or a natural forested system where plants or tree produce might be harvested informally or for subsistence when available rather than being reliably available. Trees can be a crop or more similar to plants in an agricultural system in terms of function. See further explanation in Vogt (2021).

\section{References}

Acosta J (1972) La estructura agrarian y el sector agropecuario el triunfo de la Revolucion, Economia Desarollo, 9

Babbar LI, Zak DR (1995) Nitrogen loss from coffee agroecosystems in Costa Rica: leaching and denitrification in the presence and absence of shade trees. J Environ Quality 24(2):227-33

Babin N (2015) The coffee crisis, fairtrade and agroecological transformation: impacts on land use change in Costa Rica. Agroecol Sustain Food Syst 39 (1):99-129

Bommarco R, Marini L, Vaissière BE (2012) Insect pollination enhances seed yield, quality, and market value in oilseed rape. Oecologia 169(4):1025-32. https:// doi.org/10.1007/s00442-012-2271-6 
Barratt BIP, Moran VC, Bigler F, van Lenteren JC (2018) The status of biological control and recommendations for improving uptake for the future. BioControl 63(1):155-67

Bartley R, Thomas MF, Clifford D et al. (2013) Land suitability: technical methods. A Technical Report to the Australian Government for the Flinders and Gilbert Agricultural Resource Assessment (FGARA) Project, CSIRO, Australia

Barot S, Allard V, Cantarel A, Enjalbert J et al. (2017) Designing mixtures of varieties for multifunctional agriculture with the help of ecology. A review. Agronomy Sustain Dev 37:13

Batari P, Galle R, Riesch F et al. (2017) The former Iron Curtain still drives biodiversity-profits trade-offs in German agriculture. Nat Ecol Evol 1:1279-84

Boudh S, Singh JS (2019) Pesticide Contamination: Environmental Problems and Remediation Strategies. In: Bharagava R, Chowdhary P (eds) Emerging and Eco-Friendly Approaches for Waste Management. Springer, Singapore. https://doi.org/10.1007/978-981-10-8669-4_12

Boutin C, Jobin B (1998) Intensity of agricultural practices and effects on adjacent habitats. Ecol Appl 8:544-57. https://doi.org/10.1890/1051-0761(1998)008 [0544:IOAPAE]2.0.CO;2

Bohn T, Amundsen P (2004) Ecological interactions and evolution: forgotten parts of biodiversity. BioScience 54(9):804-5

Bommarco R, Kleijn D, Potts SG (2012) Ecological intensification: harnessing ecosystem services for food security. Trends Ecol Evol 28(4):230-38

Brawn JD (2017) Implications of agricultural development for tropical biodiversity. Tropical Conserv Sci 10:1940082917720668

Brown TC, Bergstrom JC, Loomis JB (2007) Defining, valuing and providing ecosystem goods and services. Nat Resour J 47(2):329-76

Brown VK, Gange AC (2002) Tritrophic below and above ground interactions in succession. In: Tscharntke T, Hawkins B (eds) Multitrophic level interactions. Cambridge University Press, pp. 197-222

Bullock JM, Dhanial-Adams KL, Milne A, Oliver TH, Todman LC, Whitmore AP, Pywell RF (2017) Resilience and food security: rethinking an ecological concept. J Ecol 105(4):880-84

Caicedo BLC, Guerrero HAC, Roux J, Wingfield MJ (2013) New coffee (Coffea Arabica) genotypes derived from Coffea canephora exhibiting high levels of resistance to leaf rust and ceratocystis canker. Tropical Plant Pathol 38 (6):485-94

Carvalheiro LG, Kanin WE, Kiel P, Aguirre-Gutierrez J et al. (2013) Species richness declines and biotic homogenisation have slowed down for NWEuropean pollinators and plants. Ecol Lett 16(7):870-8

Cerda C, Bidgeain I (2018) Spectrum of concepts associated with the term 'biodiversity': a case study in a biodiversity hotspot in South America. Environ Monit Assess 190(207):207

Cohen M (2015) Paradigm shift: how expert opinions keep changing on life, the universe, and everything. Imprint Academic

Daily G, Söderqvist T, Aniyar S et al. (2000) The value of nature and the nature of value. Science 289(5478):395-6. https://doi.org/10.1126/science.289.5478.395

Davis MA (2003) Biotic globalisation: does competition from introduced species threaten biodiversity? BioScience 53(5):481-89

Delong DC, Jr. (1996) Defining biodiversity. Wildlife society bulletin 24(4):738-49

Diaz-Briquets S, Perez-Lopez J (2000) Conquering nature: the environmental legacy of socialism in Cuba. Pittsburgh University of Pittsburgh, 2872-80.

Dunlap RE (2010) The new environmental paradigm scale: from marginality to worldwide use. J Environ Educ 40(1):3-18

Ehrlich PR (2009) Cultural evolution and the human predicament. Trends Ecol Evol 24(8):409-12

FAOStat (2011). Production, crops, coffee green. Viewed 2013. http://FAOstat.org/ site/567/DesktopDefault.aspx?PageID =567\#ancor

Fischer J, Abson DJ, Bergsten A et al. (2017) Reframing the Good-biodiversity challenge. Trends Ecol Evol 32(5):335-45

Fischer J, Fazey I, Briese R, Lindenmayer DB (2005) Making the matrix matter: challenges in Australian grazing landscapes. Biodivers Conserv 14:561-78

Florez E, Hernandez MR (1981) Fluctuacion de la poblacion del mirador de las hojas del café to, Leucoptera coffella y de sus enemigos naturales en el Valle del Cauca. Revista de la Sociedad Colombiana de Entomologia 7:29-38

Forman R, Godron M (1986) Landscape ecology. Wiley, New York

Forman R (1995) Some general principles of landscape and regional ecology. Landsc Ecol 10(3):133142

Galdeano-Gómeza E, Cespedes-Lorente J, Martinez-del-rio J (2008) Environmental performance and spillover effects on productivity: Evidence from horticultural firms. J Environ Manage 88(4):1552-61

Geist HJ, Lambin EF (2002) Proximate causes and underlying driving forces of tropical deforestation: tropical forests are disappearing as the result of many pressures, both local and regional, acting in various combinations in different geographical locations. BioScience 52(1):143-50

Gunderson LH (2000) Ecological resilience-in theory and and application Ann Rev Ecol Systemat 31:425-39
Hass AL, Kerman UG, Tscharntke T, Clough Y, Baillod AB, Sirami C, Fahrig L, Martin JL, Baudry J, Bertrand C, Bosch J (2018) Landscape configuration heterogeneity by small-scale agriculture, not crop diversity, maintain pollinations and plant reproduction in West Europe. Proc Royal Soc Biol Sci 285 (1872):20172242

Hindorf H, Ormondi CO (2011) A review of the three major fungal diseases of coffee arabica. In the rainforests of Ethiopia and progress in breeding for resistance in Kenya. J Adv Res 2(2):109-210

Holling CS (1973) Resilience and stability of ecological systems. Ann Rev Ecol System 4:1-23

Holt AN (2006) Biodiversity definitions vary within the discipline. Nature 444 (146): 146

Howard B, Braat LC, Bugter RJF et al. (2018) Taking stock of the spectrum of arguments for biodiversity. Biodiver Conserv 27(7):1561-74

ICO (2018) Country data on the global coffee trade. www.ico.org/profile_e.asp

Imai N, Samejima H, Langner A, Ong RC, Kita S, Titin J, Chung AY, Lagan P, Lee YF, Kitayama K (2009) Co-benefits of sustainable forest management in biodiversity conservation and Carbon sequestration. PloS ONE 4:e8267

Innes C, Annand M, Bausch CT (2013) The impact of human-environment interactions on the stability of forest-grassland mosaic ecosystems. Sci Rep 3 (3):2689

ITC (International Trade Centre) (2011) The coffee exporters guide. 3rd edn https://www.intracen.org/WorkArea/DownloadAsset.aspx?id=58068

Maxim L, Van der Sluijs JP (2013) Seed-dressing systemic insecticides and Honeybees Late Lessons from Early Warnings: Science, Precaution, Innovation, European Environment Agency (EEA), 401-38.

Oijem JO, de Ridder N, Vanlauwe B, Giller KE (2011) Social-ecological niche: a conceptual framework for integration of legumes in smallholder farming systems. Int J Agric Sustainability 4(1)

Jabareen Y (2009) Building a conceptual framework, philosophies, definitions and procedure. Int J Qualitat Methods 8(4):49-62

Jaramillo J, Stefamous M, Muchugu EN et al. (2013) Climate Change or Urbanisation? Impacts on a traditional coffee production system in East Africa over the last 80 years. PLoS ONE 8:e51815

Jeltsch FD, Bonte D, Pe'er G et al. (2013) Integrating movement ecology with biodiversity research - exploring new avenues to address spatiotemporal biodiversity dynamics. Mov Ecol 1:6. https://doi.org/10.1186/2051-3933-1-6

Jha S, Bacon CM, Philpott SM et al. (2014) Shade Coffee: Update on a Disappearing Refuge for Biodiversity. BioScience 64(5):416-28. https://doi.org/ 10.1093/biosci/biu038

Johnson AF, Lidstrom S (2018) The balance between concepts and complexity in ecology. Nat Ecol Evol 2:585-7

Karungi J, Namibia N, Inala AR, Jonsson M, Kyamanywa S, Ekbom B (2015) Relating shade levels and distance from natural vegetation with Hemiptera pests and predators occurrence on coffee. J Appl Entomol 139(9):669-78

Kleijn D, Winfree R, Bartomeus I et al. (2015) Delivery of crop pollination services is an insufficient argument for wild pollinator conservation. NatCommun 6:7414. https://doi.org/10.1038/ncomms8414

Klatt BK, Holzschuh A, Westphalia C et al. (2014) Bee pollination improves crop quality, shelf life and commercial value. Proc Biol Sci 281(1775):20132440

Kleijn D, Linders TEW, Stip A, Biesmeijer JC, Wäckers FL, Bukovinszky T, Carvalheiro L (2018) Scaling up effects of measures mitigating pollinator loss from local-to landscape-level population responses. Methods Ecol Evol 9(7):1727-38

Knudsen GR, Dandurand LC (2014) Ecological complexity and the success of fungal biological control agents. Adv Agric 2014:542703

Kovacs-Hostyanszki A, Espindola A, Vanbergen AJ (2017) Ecological intensification to mitigate impacts of conventional intensive land use on pollinators and pollination. Ecol Lett 20(5):673-89

Lanz B, Dietz S, Swanson T (2018) The expansion of modern agriculture and biodiversity decline: an integrated assessment. Ecol Econ 144:260-77

Larsen AE, Gaines SD, Deschênes O (2017a) Agricultural pesticide use and adverse birth outcomes in the San Joaquin Valley California. Nat Commun 8(302):1-9

Larsen AE, Noack F (2017b) Identifying the landscape drivers of agricultural insecticide use leveraging evidence from 100,000 fields. PNAS 114(21):5473-8

Leopold A (1939) The farmer as a conservationist. Am Forests 45:294-99. 316, 323

Letourneau DK, Bothwell SG (2008) Comparison of organic and conventional farms: challenging ecologists to make biodiversity functional. Front Ecol Environ 6(8):430-8

Lichtenberg EM, Kennedy CM, Kremen C et al. (2017) A global synthesis of the effects of diversified farming systems on anthropoid diversity within fields and across agricultural landscapes. Global Change Biol 23(11):4946-57

Lin BB (2001) Resilience in agriculture through crop diversification: adaptive management for environmental change. BioScience 61(3):183-93

Luckett S (2004) Environmental paradigms: biodiversity conservation, and critical systems thinking. Syst Practice Action Res 17(5):511-34

Manners R, van Etten J (2018) Are agricultural researchers working on the right crops to enable food and nutrition security under future climates. Global Environ Change 53:182-94 
Odum HT (1970) Environment, Power, and Society for the Twenty-First Century: The Hierarchy of Energy. John Wiley and Sons Ltd, New York

Oliveira LC, Estrada A (2017) Agroecosystems. The International Encyclopedia of Primatology. John Wiley \& Sons Inc.

Ostrom E (1990) Governing the commons: the evolution of institutions for collective action. Cambridge University Press

PAHO (Pan american health organisation) (2002) Health in the Americas. 2002 edn. Vol. II. Scientific and Technical Publication No. 587. Pan American Health Organization. Pan American Sanitary Bureau, Regional Office of the World Health Organization

Pascual U, Balvanera P, Díaz S et al. (2017) Valuing nature's contributions to people: the IPBES approach. Curr Opinion Environ Sustain 26:7-16

Pe'er G, Zingrebe Y, Hauck J (2016) Adding some green to the greening: improving the EUs ecological focus for biodiversity and farmers. Conserv Lett 10(5):517-30

Peterson B, Snapp S (2015) What is sustainable intensification? Views from experts. Land Use Policy 46:1-10

Redman CL (1999) Concepts that organise our thoughts. In Human Impact on Ancient Environments. The University of Arizona Press, pp. 35-42

Risser PG (1987) Landscape ecology: state of the art. In Landscape heterogeneity and disturbance. Turner M.G. (ed) Springer-verlag, New York, pp. 3-14

Rodrigues TF, Chiarello AG (2018) Native forests within and outside protected areas are key for nine-banded armadillo (Dasypus novemcinctus) occupancy in agricultural landscapes. Agric Ecosyst Environ 266:133-1

Rosset P, Benjamin M (eds) (1994) The greening of the revolution: Cuba's experiment with organic agriculture. Ocean Press

Russo L, Memmott J, Montoya D, Shea K, Buckley YM (2014) Patterns of introduced species interactions affect multiple aspects of network structure in plant-pollinator communities. Ecology 95:2953-63. https://doi.org/10.1890/13-2229.1

Ruzicka M, Misovicova R (2009) The general and special principles in landscape ecology. Ekologia 28(1):1-6

Scheu S, Setala H (2002) Mutlitrophic interactions in decomposed food-webs. In: Tscharntke T, Hawkins B (eds) Multitrophic level interactions. Cambridge University Press, Cambridge, pp. 223-64

Scholes RG, Biggs R (2005) The biodiversity intactness index. Nature 434:45-49

Schroth G, McNeely JA (2011) Biodiversity conservation, ecosystem services and livelihoods in tropical landscapes: towards a common agenda. Environ Manag 48:229-36

Sepulveda RB, Carrillo AA (2015) Soil erosion and erosion thresholds in an agroforestry system of coffee (Coffea arabica) and mixed shade trees (Inga spp and Musa spp) in Northern Nicaragua. Agric Ecosyst Environ 210:25-35

Shennan C, Krupnik TJ, Baird G et al. (2017) Organic and conventional agriculture: a useful framing? Ann Rev Environ Resour 42:317-46

Small N, Munday M, Durance I (2017) The challenge of valuing ecosystems services that have no material benefits. Global Environ Change 44:57-67

Sonter L, Herrera D, Barrett DJ (2017) Mining drives extensive deforestation in the Brazilian Amazon. Nature 8:1013

Takacs D (1996) The idea of biodiversity: philosophies of paradise. John Hopkins Press

Tittonell P (2014) Ecological intensification of agriculture-sustainable by nature. Curr Opin Environ Sustain 8:53-61

Toniutti L, Breitler J et al. (2017) Influence of environmental conditions and genetic background of arabica Coffee (c. Arabica L) on leaf rust (hemileia vastatrix) pathogenesis. Front Plant Sci 8:2025

Toledo RM, Santos RF, Baeten L, Perring MP, Verheyen K (2018) Soil properties and neighbouring forest cover affect above-ground biomass and functional composition during tropical forest restoration. Appl Veg Sci. 21:179-89. https://doi.org/10.1111/avsc. 12363

Quinteros E, Ribo A, Mejia R et al. (2017) Heavy metals and pesticide exposure from agricultural activities and former agrochemical factory in a Salvadoran rural community. Environ Sci Pollut Res 24(2):1662-76

Vandermeer J, Jackson D, Perfecto I (2014) Qualitative dynamics of the coffee rust epidemic: educating institution with theoretical ecology. BioScience 64(3):210-18

Vergara CH, Badano EI (2009) Pollinator diversity increases fruit production in Mexican coffee plantations: the importance of rustic management systems. Agric Ecosyst Environ 129(1):117-23

Vogt MAB (2017) Toward functional pollinator abundance and diversity: comparing policy response for neonicotinoid use to demonstrate a need for cautious and well-planned policy. Biol Conser 215:196-212

Vogt MAB (2019a) Comparing and seeking complementarity between four farm designs. Global Ecol Conserv 17:e00520
Vogt M (2019b) Variance in Approach Toward a 'Sustainable' Coffee Industry in Costa Rica: Perspectives from Within; Lessons and Insights. Ubiquity Press, London

Vogt M (2019c) Developing stronger association between market value of coffee and functional biodiversity. Environ Manag 269:110777

Vogt MAB (2019d) Juggling sustainability certifications in the Costa Rica coffee industry. In: Vogt M (ed) Sustainability certification schemes in the agricultural and natural resource sectors: outcomes for society and the environment. Chapter 11. Taylor \& Francis, London

Vogt M, Englund O (2019) Biodiversity outcomes associated with sustainability certifications: contextualising understanding and expectations, and allowing for ambitious intentions. In: Vogt M (ed) Sustainability certifications schemes in the agricultural and natural resource sectors: outcomes for society and the environment. Chapter 3. Taylor \& Francis, London

Vogt MAB (2020) Developing stronger association between market value of coffee and functional biodiversity. J Environ Manag 269:110777

Vogt MAB (2021) Agricultural wilding: rewilding for agricultural landscapes through an increase in wild productive systems. J Environ Manager 284:112050

Walmsley DJ, Lewis GJ (1993) People and environment: behavioural approaches in human geography. Routledge, New York, London

Walmsley DJ, Lewis, GJ (1984) Human geography: behavioural approaches. Longman, New York, London

Weiner J (2017) Applying plant ecological knowledge to increase agricultural sustainability. J Ecol 105(4):865-70

Western D (2001) Human-modified ecosystems and future evolution. PNAS 98 (10):5458-65

Wilson EO (1988) Biodiversity. National Forum on Biodiversity (1986, Washington, DC), Institute of Medicine, National Academy of Sciences USA, Washington, DC

Wilson S, Mitchell GW, Pasher J et al. (2017) Influence of crop type, heterogeneity and woody structure on avian biodiversity in agricultural landscapes. Ecol Indic 83:218-26

\section{Acknowledgements}

The affiliation for this article recognises that it was originally part of a $\mathrm{PhD}$ dissertation with associated acknowledgements and funding. Peer review organised by the journal has improved the article for publication.

\section{Competing interests}

The author declares no competing interests.

\section{Additional information}

Supplementary information The online version contains supplementary material available at https://doi.org/10.1057/s41599-021-00837-3.

Correspondence and requests for materials should be addressed to M.A.B.V.

Reprints and permission information is available at http://www.nature.com/reprints

Publisher's note Springer Nature remains neutral with regard to jurisdictional claims in published maps and institutional affiliations.

cc) (i) Open Access This article is licensed under a Creative Commons Attribution 4.0 International License, which permits use, sharing, adaptation, distribution and reproduction in any medium or format, as long as you give appropriate credit to the original author(s) and the source, provide a link to the Creative Commons license, and indicate if changes were made. The images or other third party material in this article are included in the article's Creative Commons license, unless indicated otherwise in a credit line to the material. If material is not included in the article's Creative Commons license and your intended use is not permitted by statutory regulation or exceeds the permitted use, you will need to obtain permission directly from the copyright holder. To view a copy of this license, visit http://creativecommons.org/ licenses/by/4.0\%

(C) The Author(s) 2021, corrected publication 2021 